\title{
Students' Perceptions of the Use of Asynchronous Discussion Forums, Quizzes, and Uploaded Resources
}

\author{
Nurul Shida, Sharifah Osman, Abdul Halim Abdullah
}

\begin{abstract}
This research inspects students' perceptions of the utilisation of asynchronous discussion forums, quizzes, and uploaded resources in platform CIDOS LMS among polytechnic students. There has been an expansion in the utilisation of LMS in many levels of education in polytechnic institutions. CIDOS LMS has variety tools examples assignments, video, scorm, and tutorial. Purposive sampling was used to choose the research participants for this study. The participants consisted of 60 diploma students from Polytechnic Sultan Ibrahim who are enrolled in a Mathematics course. The Cronbach's alpha of the instruments is 0.899. The questionnaire was divided into four catego-ries. The categories addressed students' perceptions of CIDOS LMS tools, namely the discussion forums, quizzes, and the utilisation of uploaded resources. Likert scale rated from strongly disagree to strongly agree. All the data were analysed using IBM Statistical to obtain the percentages, frequencies, means, standard deviations, independent sample t-test, and Pearson correlation. The results of this study show that the practice of CIDOS LMS among engineering students at Polytechnic Sultan Ibrahim is at a high level during the learning process. Further research would explore the educators' need to figure out the best ways in CIDOS LMS to engage students as the millen-nial generation continues to dominate the workforce.
\end{abstract}

Index Term: Asynchronous Discussion Forums; Quizzes; Uploaded Resources; Polytechnic; CIDOS LMS.

\section{INTRODUCTION}

In polytechnic, an e-learning activity in blended learning using LMS is known as CIDOS LMS. Previous studies have reported that the use of LMS has grown exponentially and it is becoming ubiquitous in current higher education [1]. LMS supports face-to-face education and enables enhanced communication and interaction among instructors and students [2]. [3] stated that all teachers must be digitally literate with the present technology and only then can they work together with developers to create change. The LMS includes learning tools, assessment tools, and support tools [4].

Asynchronously indicates to the way that the discussions occur over a period of time with members signing on at various times, as per their own comfort, and contributing

Revised Manuscript Received on September 22, 2019.

Nurul Shida, Politeknik Ibrahim Sultan, nurul_ashida@yahoo.com

Sharifah Osman, Faculty of Education, Universiti Teknologi Malaysia

Abdul Halim Abdullah, Faculty of Education, Universiti Teknologi Malaysia posts to the discussion [5]. They provide a platform for collaborative and interactive learning [6], making the learning and education procedure easy in the distance education world [7]. LMS discussion forums make for easy monitoring and commenting on other groups' processes and files in which sending and receiving of materials are not delivered simultaneously [9]. [10] showed that teachers and students can post messages to each other and keep track of individual discussions for an effective group. The educators who is effectively engaged in checking, assessing, and giving input with respect to student can gather important experiences into the different needs of students in each section of a course [11].

[12]. indicated that customized e-quizzes teach and assess the student according to the student's abilities. Moreover, the frequency of quizzes helps students to stay focused, study more, be more engaged with the subject [13], increase engagement, improve understanding [14], and stay [15]. Online quizzes may be of specific value given their capacity to connect with students during content dissemination [16]. [3] stated that with online quizzes, students can identify the areas that they will need to review and questions that will give a very useful constant feedback on student answers. Several quizzes are available for the participants for self-assessment [17].

[18]. investigated the multimedia resources and interactive tasks that have contributed to developing their independent and collaborative learning skills. The use of the physical space and material resources is able to engage students [19]. [20] demonstrated that the LMS affords functionality to follow or trace student activities and capture data sets to help improve the learning experience. The proficiency of the LMS depends on how effectively the users can gets to its multi-faceted benefits when collaborating with it [21] The functions of the LMS can make for interactive collaboration

[22]. The significance of the LMS interface designs augment the utilisation and benefit of learning resources, the perceived value of assessment functions working successfully in online systems, and the development of elective types of communication and collabo-ration [23]. [24] pointed out that he LMS has much potential to transform lecturers' practices with regard to teaching. It was found that most respondents have used the LMS at $71.6 \%$ [25]. 
Computer-mediated communication tools like discussion forums provide ways for learners to interact [26]. [27] noted that such forums would provide opportunities to other students and their instructor to give comments and support one another, thus strengthening learner-learner and learner-instructor interactions. When online discussion forums are effectively facilitated, they can foster inclusion and serve as a democratising force, allowing all voices to become part of the conversation, even those students who tend to remain silent in a face-to-face class because they feel shy or anxious [28]. Discussion boards, virtual chat rooms, and instant messages provide forums [29] for questioning [30].

\section{Literature ReVIEW}

[31]. discovered quizzes were used to help determine the mastery of content. Quizzes are relatively contemporaneous with other learning tools that require students to "retrieve" knowledge [32].

[33]. posited that students were given frequent quizzes to provide information to the professor about how well students understood the course material. [34] mentioned moderator analyses found that quizzes positively affected the effectiveness and attractiveness of blended learning. They were able to help teachers to deliver learn-ing materials but also at the same time track students' performance and participation [35].

For example, if students had difficulty with quizzes or answered quickly and did not read the answers, and interviews showed that students were not interested or did not like the delivery or under-stand the delivery of the content, then the teaching method for the next lesson was changed [31]. [32] discussed that students taking longer quizzes suffered from survey fatigue and ceased to engage in the learning activity seriously. In addition, quizzes replaced the application of certain core techniques [36]. Quizzes are used to inform students about their learning achievement [37]. Online quizzes made available to the students each week to overcome the barrier of students often do not raise questions or indicate their challenges in understanding certain concepts [38]. Moreover, it is easier for the lecturer to create, monitor, mark, and provide feed-back to students online [39-40]. A.

Previous research has shown that $85 \%$ of them indicated that ac-cessing project resources on demand was very useful [41]. All respondents indicated that they would likely use web-based re-sources as tools for increasing course content understanding [42]. Students' engagement in the utilisation and use of the different assets in blended learning demonstrated the great utilisation of the highlights and students were happy with them [43]. (K

\section{RESEARCH QUESTION}

The following research questions guided this study:

- $\quad$ Are there any significant differences of student perceptions of the use of asynchronous discussion forums, quizzes, and uploaded resources in CIDOS LMS?
- $\quad$ Are there any significant differences between gender for student perceptions of the use of asynchronous discussion forums, quizzes, and uploaded resources in CIDOS LMS?

- Are there any significant differences between CIDOS LMS towards gender?

\section{ObJectives of The STUdy}

This research was intended to explore student perceptions of the use of asynchronous discussion forums, quizzes, and uploaded resources. This study aim to examine the utilisation of tools in CIDOS LMS.

\section{Methodology}

A total of 60 respondents were selected as a sample consisting of lecturers in the engineering department. The population of the study is from Polytechnic Sultan Ibrahim. For the purposes of this study, the researchers used the questionnaire by [44] as an instrument. The questionnaire is divided into four parts, namely A, B, C, and D. Part A consists of two questions regarding the respondents' background information. Part B contains questions that will

\section{Fig 1: Conceptual framework}

assess the asynchronous discussion forums and quizzes while part C is about uploaded resources. For parts B, C, and $\mathrm{D}$ in the questionnaire, a Likert scale of 4 points were used; 1-strongly disagree, 2-disagree, 3-agree, 4-strongly agree. Data were analysed using IBM statistical for determining the average mean score, standard deviation, t-test, Pearson correlations, and independent sample t-test and to look for differences in the desired aspect.

\section{Findings}

In terms of frequency of respondents by gender, the majority of respondents $(\mathrm{n}=35)$ are male $(58.3 \%)$, while $41.7 \%(\mathrm{n}=25)$ are female respondents as presented in Table 1. For departments, $61.7 \%$ are from the Department of Mechanical Engineering and $38.3 \%$ are from the Department of Electrical Engineering. 
Table 1: Demographic Information about the Participants

\begin{tabular}{cccc}
\hline Variables & & Frequency & Percent \\
\hline \multirow{2}{*}{ Gender } & Male & 35 & 58.3 \\
& Female & 25 & 41.7 \\
\multirow{2}{*}{ Department } & JKM & 37 & 61.7 \\
& JKE & 23 & 38.3 \\
\hline
\end{tabular}

Table 2 provides the mean, standard deviation, and interpretation for the asynchronous discussion forums. From the analysis, it shows that the utilisation of LMS from the asynchronous discussion forums construct is at a high level with the mean of 3.25 (SD 0.52508). The analysis show that the highest mean value is for item F3, 3.40 ( $\mathrm{SD}=0.616$ ), which is students are ready to make speculations regarding issues being examined and make sensible conclusions. Mean value is 2.85 ( $\mathrm{SD}=0.988)$, which is the lowest mean for item F7 where students are bothered to take an interest in any action identified with the discussion forum for getting course grades.

Table 2: Mean, Standard Deviation and Interpretation for Asynchronous Discussion Forums Constructs

\begin{tabular}{llll}
\hline Item & Mean & Std. Deviation & $\begin{array}{l}\text { Interpretati } \\
\text { on }\end{array}$ \\
\hline F1 & 3.32 & .676 & High \\
F2 & 3.35 & .709 & High \\
F3 & 3.40 & .616 & High \\
F4 & 3.37 & .637 & High \\
F5 & 3.07 & .899 & High \\
F6 & 3.42 & 0.645 & High \\
F7 & 2.85 & 0.988 & Moderate \\
F8 & 3.22 & 0.904 & High \\
Total & 3.25 & 0525 & High \\
Mean & & &
\end{tabular}

As shown in Table 3, the results of the descriptive analysis show that the utilisation of LMS from the quizzes construct among students is high (mean=3.1, SD=. 567). The analysis shows that item Q4 has the highest mean, which is the tasks in a quiz encourage to tackle issues identified with what the students realise with the mean value of $3.38(\mathrm{SD}=.640)$. Item Q7 with mean value is $2.63(\mathrm{SD}=1.025)$ where the computer feedback students get from the quiz is more useful than the input given by the lecturers is the lowest mean.

Table 3: Mean, Standard Deviation and Interpretation for Quizzes Con-structs

\begin{tabular}{llll}
\hline Item & Mean & Std. Deviation & Interpretation \\
\hline Q1 & 3.02 & .911 & High \\
Q2 & 3.13 & .812 & High \\
Q3 & 3.38 & .640 & High \\
Q4 & 3.48 & .676 & High \\
Q5 & 3.22 & .739 & High \\
Q6 & 2.90 & 1.037 & Moderate \\
Q7 & 2.63 & 1.025 & Moderate \\
Q8 & 3.13 & .833 & High \\
Total Mean & 3.11 & 0.567 & High \\
\hline
\end{tabular}

The mean value and the standard deviation level of uploaded re-sources constructs in the LMS as presented in Table 4. From the analysis, it was found that the level of uploaded resources is at a high level with the mean score of
$3.16(\mathrm{SD}=0.598)$. The result of the analysis shows that the highest mean value is for the U4 item, which is the resources helped to solve issues identified with the course with the mean value of 3.37 ( $\mathrm{SD}=0.637)$. The lowest mean value is $2.63(\mathrm{SP}=1.025)$, which is for the $\mathrm{U} 2$ item where the resources did not offer assistance accomplish the goals of the course.

Table 4: Mean, Standard Deviation and Interpretation for Uploaded Re-sources Constructs

\begin{tabular}{llll}
\hline Item & Mean & $\begin{array}{l}\text { Std. } \\
\text { Deviation }\end{array}$ & Interpretation \\
\hline U1 & 3.35 & 0.633 & High \\
U2 & 2.63 & 1.025 & Moderate \\
U3 & 3.28 & 0.666 & High \\
U4 & 3.37 & 0.637 & High \\
Total & 3.16 & 0.598 & High \\
Mean & & &
\end{tabular}

T-tests were used to compare the mean difference between gen-ders. The t-test results are shown in Error! Reference source not found. And Table 6. The analysis was carried out to see whether there are significant mean differences between male and female students for each construct (asynchronous discussion forums, quizzes, and uploaded resources). The summary of statistical test results shows that there is no significant difference in the elements of the forum $(\mathrm{p}=.222)$ and quiz $(\mathrm{p}=.549)$ between male and female students. However, there is a significant difference in uploaded resources between gender $(p=.029)$.

Table 5: The T-Test Compares the Mean of LMS Constructs to Gender

\begin{tabular}{llllll}
\hline Variables & Gender & $\mathrm{N}$ & Mean & $\begin{array}{l}\text { Std. } \\
\text { Deviation }\end{array}$ & $\begin{array}{l}\text { Std. } \\
\text { Error } \\
\text { Mean }\end{array}$ \\
\hline Forum & Male & 35 & 3.3189 & 0.49929 & 0.0844 \\
& Female & 25 & 3.15 & 0.55434 & 0.11087 \\
Quiz & Male & 35 & 3.15 & 0.60391 & 0.10208 \\
Uploaded & Female & 25 & 3.06 & 0.51931 & 0.10386 \\
Resources & Memale & 25 & 3.3 & 0.55836 & 0.09438 \\
\hline
\end{tabular}

Table 6: T-test Analysis

\begin{tabular}{llll}
\hline Variables & Sig. & $\mathrm{t}$ & $\mathrm{df}$ \\
\hline Forum & 0.681 & 1.234 & 58 \\
Quiz & 0.064 & 0.603 & 58 \\
Uploaded & 0.856 & 2.243 & 58 \\
Resources & & & \\
\hline
\end{tabular}

A Pearson's correlation was computed on the total score of each construct. Using SPSS, the relationship was computed, and as seen in Table 7, there was a significant correlation between the three constructs of the LMS. 
Table 7: Pearson Correlations Between Asynchronous Discussion Forums, Quizzes, and Uploaded Resources

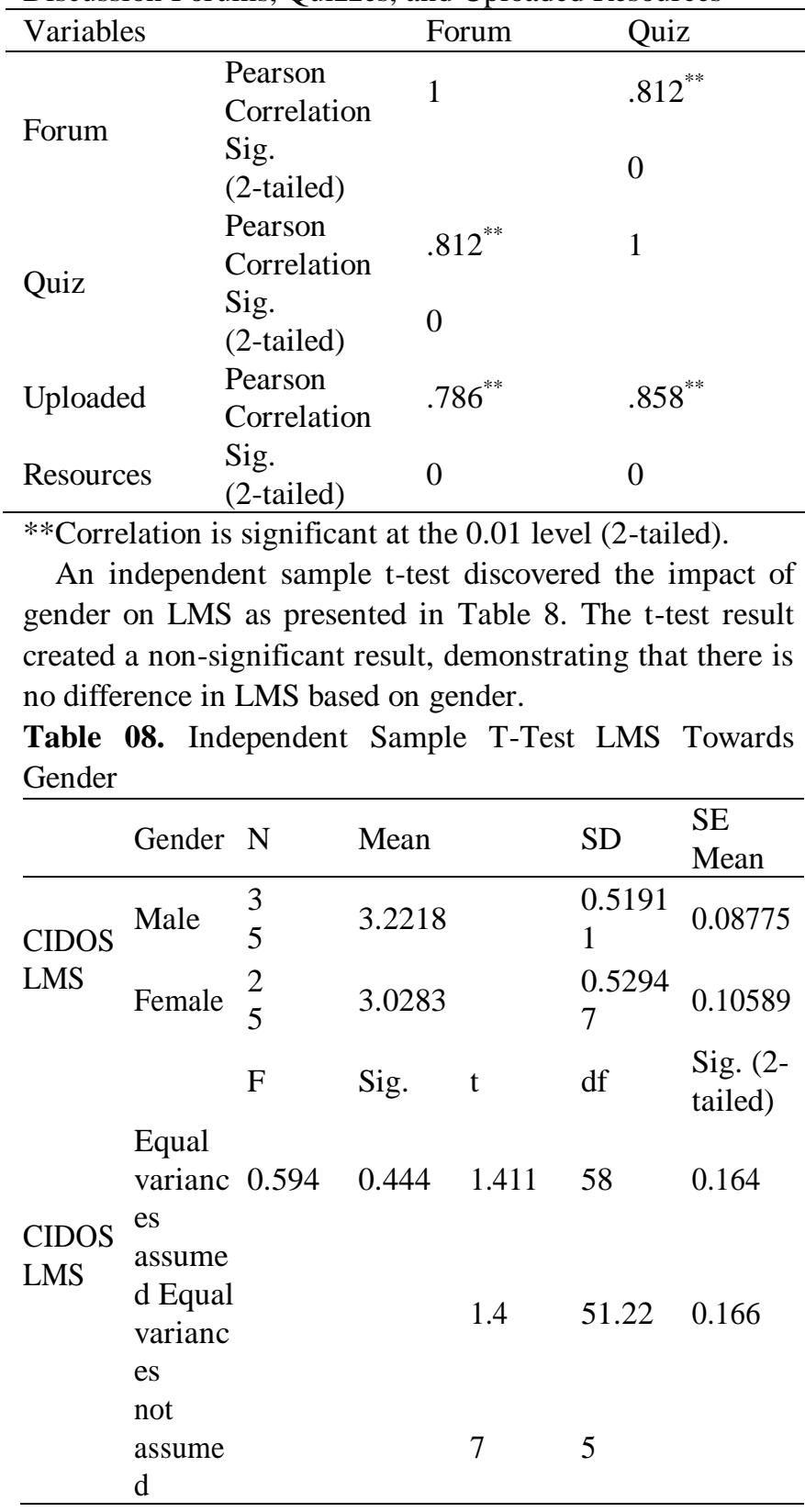

\section{CONCLUSION}

The findings show that the practice of LMS for engineering stu-dents at Polytechnic Sultan Ibrahim is at a high level in the learn-ing process. It is a positive sign that students have practiced the CIDOS LMS during the teaching and learning process. Further analysis showed that the asynchronous discussion forum con-structs have the highest mean value compared to others. These findings further support the idea of [45] in which meaningful use of the platform and peer-to-peer learning could be promoted by introducing collaborative learning activities utilising the discus-sion forums. It was shown that uploaded resources followed by quizzes are also high. Consistent with the findings by [46], it was found that active students performed better in the quizzes and examinations compared to the less active students. There is no uncertainty in saying that students' concern is in uploaded re-sources. With the emphasis on the benefits of the LMS, educators can make a variety of quizzes online that can attract students. The LMS could possibly contribute to the increment of the institutional reputation, enhance the nature of teaching, and give adaptability in students' life-long learning. Based on the research, it was found that there was no difference in LMS engagement based on gender. Further research might explore educators' need to figure out the best variety of ways in the LMS to engage students of the millen-nial generation to continue to dominate the workforce.

\section{REFERENCES}

[1] Kim, J. H., Park, Y., Song, J., \& Jo, I. (2014). Predicting students' learning performance by using online behavior patterns in blended learning environments: Comparison of two cases on inear and non-linear model. International Conference on Educational Data Mining, (July 2015), 407-408. https://doi.org/10.13140/2.1.4840.7040

[2] Fyntanoglou, D., \& Kartaloglou, E. (2015). Improving the Interaction and Communication through the LMS Open eClass in Blended Learning, 122.

[3] Elena, P. (2015). Technology acceptance in blended learning: The case of Jönköping International Business School.

[4] George, R., Morin, D., \& Thomas, J. D. E. (2012). Computers in Human Behavior Critical thinking in E-learning environments. https://doi.org/10.1016/j.chb.2012.03.025

[5] Hand, K. G. (2015). Descriptive Post Titles as Advance Organizer: Ef-fects on Critical Thinking and Cognitive Load in Asynchronous Thread-ed Discussions.

[6] Zafar, S., Safdar, S., \& Malik, B. (2015). Online behaviour of students in a new blended learning course: An experience report. Proceedings of IEEE International Conference on Teaching, Assessment and Learning for Engineering: Learning for the Future Now, TALE 2014, (December), 387-394

[7] Haghparast, M., Nasaruddin, F. H., \& Abdullah, N. (2014). Cultivating Critical Thinking Through E-learning Environment and Tools: A Re-view. Procedia - Social and Behavioral Sciences, 129, 527-535. https://doi.org/10.1016/j.sbspro.2014.03.710

[8] Pektas, S., \& Gurel, M. (2014). Blended learning in design education: An analysis of students' experiences within the disciplinary differences

[9] framework. Australasian Journal of Educational Technology, 30(1), 31-44. Retrieved from http://ascilite.org.au/ajet/submission/index.php/AJET/article/view/372

[10] Lestari, I., \& Hendradjaya, B. (2014). The application model of learning management system quality in asynchronous blended learning system. Proceedings of 2014 International Conference on Electrical Engineering and Computer Science, ICEECS 2014, (November), 223-228. https://doi.org/10.1109/ICEECS.2014.7045251

[11] Prohorets, E., \& Plekhanova, M. (2015). Interaction intensity levels in blended learning environment. Procedia - Social and Behavioral Sciences, 174(3822), 3818-3823. https://doi.org/10.1016/j.sbspro.2015.01.1119

[12] MacMillan, T., Forte, M., \& Grant, C. (2014). Thematic analysis of the "games" students play in asynchronous learning environments. Journal of Asynchronous Learning Network, 18(1).

[13] Sayed, M., \& Baker, F. (2014). Blended Learning Barriers: An Investi-gation, Exposition and Solutions, 5(6), 81-85

[14] Khan, Z. R. (2014). Using Innovative Tools to Teach Computer Appli-cation to Business Students - A Hawthorne Effect or Successful Imple-mentation Here to Stay, 11(1).

[15] Morton, C. E., Saleh, S. N., Smith, S. F., Hemani, A., Ameen, A., Ben-nie, T. D., \& Toro-Troconis, M. (2016). Blended learning: how can we optimise undergraduate student engagement? BMC Med Educ, 16 , 195. https://doi.org/10.1186/s12909-016-0716-z

[16] Napier, N. P., Dekhane, S., \& Smith, S. (2011). Transitioning to blended learning: Understanding student and faculty perceptions. Journal of Asynchronous Learning Network, 15(1), 20-32. https://doi.org/10.1177/009155218701500207

[17] Van Der Westhuizen, M. E. (2016). Reconstructing English Studies in South Africa through Blended Learning, (December).

[18] Mohammadi, E., \& Mirdehghan, S. S. (2014). A CMC Approach to Teaching Phrasal-verbs to Iranian EFL Senior High School Students: The Case of Blended Learning. Procedia - Social and Behavioral Sci-ences, 98, 1174-1178. 
[19] García-Sánchez, S. (2016). Ubiquitous interaction for ESP distance and blended learners. Journal of Applied Research in Higher Education, 8(4), 489-503. https://doi.org/10.1108/JARHE-04-2014-0052

[20] Thibaut, P., Curwood, J. S., Carvalho, L., \& Simpson, A. (2014). Mov-ing across physical and online spaces: a case study in a blended primary classroom. Learning, Media and Technology, 40(4), 458-479. https://doi.org/10.1080/17439884.2014.959971

[21] Naidoo, K. (2016). Integration of Learning Analytics in Blended Learn-ing Course At a University of Technology, 4-6.

[22] Dias, S. B., Hadjileontiadis, L. J., \& Diniz, J. A. (2014). On enhancing blended-learning scenarios through fuzzy logic-based modeling of users' LMS quality of interaction the rare \& contemporary dance paradigms, 2, $765-772$. Retrieved http://ieeexplore.ieee.org/xpls/abs_all.jsp?arnumber=7295017\%5Cnhtt p://ieeexplore.ieee.org/xpls/abs_all.jsp?arnumber=7295017\&tag=1

[23] Krasnova, T., \& Demeshko, M. (2015). Tutor-mediated Support in Blended Learning. Procedia - Social and Behavioral Sciences, 166, 404-

[24] https://doi.org/10.1016/j.sbspro.2014.12.544

[25] Pye, G., Holt, D., Salzman, S., Bellucci, E., \& Lombardi, L. (2015). En-gaging diverse student audiences in contemporary blended learning en-vironments in Australian higher business education: Implications for de-sign and practice. Australasian Journal of Information Systems, 19, $1-$

[26] Siyanda Ntlabathi. (2014). Exploring Lecturer Experiences of the Use of Ict in Blended, (November).

[27] Khlaisang, J., \& Likhitdamrongkiat, M. (2015). E-learning System in Blended Learning Environment to Enhance Cognitive Skills for Learn-ers in Higher Education. Procedia-Social and Behavioral Sciences, 174, 759-767. https://doi.org/10.1016/j.sbspro.2015.01.612

[28] Parycek, P., Sachs, M., \& Schossböck, J. (2012). Interactive Technolo-gy and Smart Education Article information: Interactive Technology and Smart Education, 8(3), 161-171. https://doi.org/ITSE-02-2015-0001

[29] Jafarian, S., \& Omar, Z. (2014). Influence of Quality of Interpersonal Interaction on Learner's Critical Thinking Disposition In Blended Learning Environment In Malaysia, 1-21.

[30] Perrow, M. (2017). Strengthening the Conversation in Blended and Face-to Face Courses: Connecting Online and In-Person Learning with Crossover Protocols. College Teaching, 65(3), 97-105. https://doi.org/10.1080/87567555.2017.1300869

[31] Beckmann, J., \& Weber, P. (2015). Cognitive Presence In Virtual Col-laborative Learning: Assessing And Improving Critical Thinking In Online Discussion Forums, (2000), 51-58.

[32] Peter, E. E. (2012). Critical thinking: Essence for teaching mathematics and mathematics problem solving skills. African Journal of Mathematics and Computer Science Research, 5(3), 39-43. https://doi.org/10.5897/AJMCSR11.161

[33] Schmitt, C. P. (2016). Effects of Elearning and Blended Instruction on Student Learning.

[34] Hewitt, A. (2015). Can you learn to lawyer online? A blended learning environment case study. The Law Teacher, 49(1), 92-121. https://doi.org/10.1080/03069400.2014.991484

[35] Quint, C. L. (2015). A Study of the Efficacy of the Flipped Classroom Model in a University Mathematics Class.

[36] Spanjers, I. A. E., Könings, K. D., Leppink, J., Verstegen, D. M. L., de

[37] Jong, N., Czabanowska, K., ... Van, J. J. G. (2015). The promised land of blended learning: Quizzes as a moderator. Educational Research Re-view, 15(May), 59-74. https://doi.org/10.1016/j.edurev.2015.05.001

[38] Wong, K. T.,Hamzah, M. S. G., Goh, P. S. C., \& Yeop, M. A. B. (2016) Blended E-learning acceptance as smart pedagogical tools: An initial study in Malaysia. Turkish Online Journal of Educational Tech-nology, 15(4), 25-31.

[39] Weil, S., De Silva, T.-A., \& Ward, M. (2014). Blended learning in ac-counting: a New Zealand case. Meditari Accountancy Research, 22(2), 224-244. https://doi.org/10.1108/MEDAR-10-2013-0044

[40] Mirriahi, N., Alonzo, D., \& Fox, B. (2015). A blended learning frame-work for curriculum design and professional development. Research in Learning Technology, 23(April). https://doi.org/10.3402/rlt.v23.28451

[41] Glahn, C., Gruber, M. R., \& Tartakovski, O. (2015). Beyond Delivery Modes and Apps: A Case Study on Mobile Blended Learning in Higher Education. $\quad$ L $\quad 9307, \quad 127-140$. https://doi.org/10.1007/978-3-319-24258-
[42] Hashim, H., \& Harun, Z. (2016). Students' Feedback on Implementing Blended Learning in Semiconductor Devices, 153-157.

[43] Atef, H., \& Medhat, M. (2015). Blended Learning Possibilities in En-hancing Education, Training and Development in Developing Coun-tries : A Case Study in Graphic Design Courses, 4(4), 358-365.

[44] Freeman, C. L. (2015). Technologies for Formative Assessment: Can Web-Based Applications Transform the Allied Health Science Class-room and Improve Summative Assessment Outcome, 1-18.

[45] Irfan, A., Rasli, A., Sami, A., \& Liaquat, H. (2017). Role of Socia Me-dia in Promoting Education Tourism. Advanced Science Letters, 23(9), 8728-8731

[46] Kintu, M. J., \& Zhu, C. (2016). Student Characteristics and Learning Outcomes in a Blended Learning Environment Intervention in a Ugan-dan University, 14(3), 181-195.

[47] Mwalongo, A. I. (2014). Student Teacher and Lecturer Perceptions of the Use of Asynchronous Discussion Forums, Quizzes and Uploaded Resources for Promoting Critical Thinking.

[48] Protsiv, M., Rosales-Klintz, S., Bwanga, F., Zwarenstein, M., \& Atkins, S. (2016). Blended learning across universities in a South-North-South collaboration: a case study. Health Research Policy and Systems, 14(1),

[49] https://doi.org/10.1186/s12961-016-0136-x

[50] Junus, K., Sadita, L., \& Heru Suhartanto. (2014). Social, Cognitive, Teaching, and Metacognitive Presence in General and Focus Group

[51] Discussion: Case Study in Blended e-Learning Linear Algebra Class.

[52] Denning, S. (2007). The Secret Language of Leadership: How Leaders Inspire Action Through Narrative. San Francisco, California: Jossey Bass, John Wiley \& Sons.

[53] Deresky, H. (2017). International Business Management: Managing Across Borders, Texts and Cases. New York: Pearson.

\section{AUTHORS PROFILE}

I am Nurul Shida. my affiliation is Politeknik Ibrahim Sultan, for my email address is :nurul_ashida@yahoo.com. my area of interest is learning and quizzes.

My name is Sharifah Osman, my current affiliation is with Faculty of Education, Universiti Teknologi Malaysia. My area of interest is Education and learning.

I am Abdul Halim Abdullah, working with Faculty of Education, Universiti Teknologi Malaysia. My area of interest is Education development. 